\title{
Volume Matching for Pump and Accumulator of ABS Hydraulic Unit Based on Simulation
}

\author{
ZHENG Jin-jun ${ }^{\mathrm{a}}$, WANG Zhen ${ }^{\mathrm{b}}$ \\ College of Automobile, Jilin University, Changchun, Jilin Province 130022, P.R. China \\ azhengjj@jlu.edu.cn, ${ }^{b}$ wangzhen@jlu.edu.cn
}

Keywords: Simulation; Volume Match; ABS; Hydraulic Unit; Accumulator Model; Motor Model; Pump Model.

\begin{abstract}
A proper volume of return flow pump and accumulator is a premise for ABS control. The model of ABS hydraulic unit was established in MATLAB/Simulink, and an extreme case of ABS return flow for some domestic commercial vehicle was taken in simulation to match the volume of return flow pump and accumulator. Results show that this method can direct the design of ABS hydraulic unit.
\end{abstract}

\section{Introduction}

In the pressure decreasing process of wheel pressure regulation, there will be a certain volume of braking liquid flowing out of wheel cylinder into the low pressure reservoir (which is also called accumulator) of anti-lock braking system(ABS). If there is too much liquid in the accumulator, its pressure will become high, and this will bring a bad effect to the pressure regulation in the following control. The return flow pump can pump the liquid in the accumulator back to the high pressure pipeline in time, to realize the braking liquid cycle [1]. So in process of hydraulic unit design, it should firstly make sure that the ABS can return the braking liquid in time to achieve a rapid pressure decreasing of the wheel cylinder, and then the hydraulic unit is compact with a small size and a light weight as possible. A huge effective volume of the return flow pump and accumulator can well realize ABS functional requirements, but it also causes much functional redundancy to pay a higher cost.

In this paper, an extreme case of ABS return flow for some domestic commercial vehicle was taken to match the volume of return flow pump and accumulator, which also can give a direction for hydraulic unit design.

\section{Model Establishment}

The general method for pressure estimation, according to the quantity of braking liquid input and output of the wheel cylinder, calculates the variation of wheel cylinder pressure. Fig. 1 shows one cylinder braking circuit and liquid flow [2].

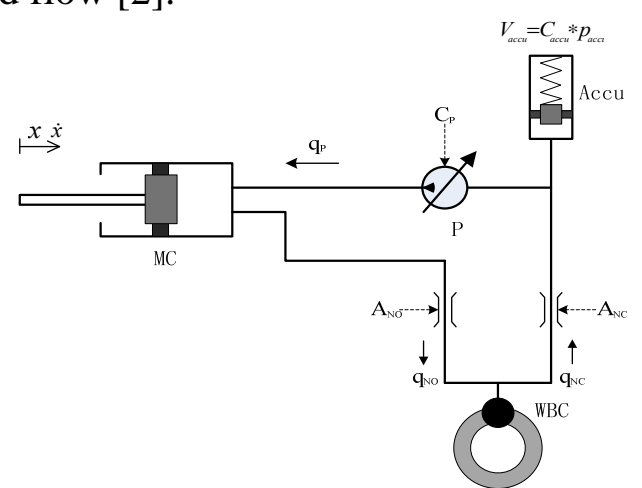

Fig 1 One wheel hydraulic circuit model

Where: MC--master cylinder; WBC--wheel brake cylinder; Accu-accumulator; P--pump

Model of Motor. The input of return flow motor is the switch voltage, and the motor outputs the drive moment to the return flow pump. And pump feeds back a resistance moment. And the 
mathematical model for motor is as formular 1: [3]

$$
\frac{d i}{d t}=\left(U-i^{*} R-k_{-} \phi^{*} \omega\right) / L
$$

Formular from DC motor torque balance relationship:

$$
\dot{\omega}=\left[k_{-} \phi^{*} i-\left(M+m_{0}\right)\right] / J
$$

Where: $U$-switch voltage; $i$-current in the motor coil; $R$-motor coil resistance; $\omega$-motor angular speed; $k \_\varphi$--electromagnetic coefficient; $L$-motor coil inductance; $M$-resistance moment from pump; $m_{0}-$ motor friction moment; $J$-moment of inertia.

Model of Pump. The return flow Pump receives the drive moment from the motor, and has the same revolution speed as the motor. Then it pumps the braking liquid from the low pressure accumulator to master cylinder. Wheel cylinders at the same axle use one pump, and the pump is a piston pump with a fixed stroke. The motor is installed eccentric with an eccentricity half of the pump stroke [4].

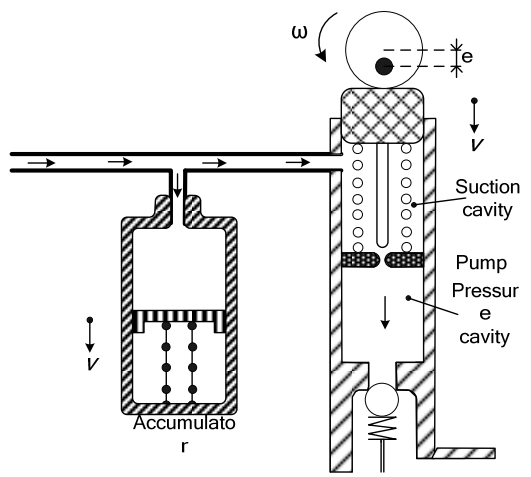

Fig 3 Construction of accumulator and pump

Volume of pressure cavity is calculated as:

$$
V=A^{*} e^{*} \sin \left(\varphi_{0}+\omega^{*} t\right)
$$

Where: $A$-area of pump piston; $e$-eccentricity; $\varphi_{0}$-is the initial angle of eccentric wheel; $\omega$-motor angular speed; $\mathrm{t}$ - time.

And the flow quantity is calculated as:

$$
q=\dot{V}=A^{*} e^{*} \cos \left(\varphi_{0}+\omega * t\right) * \omega
$$

And equivalent pressure of the pump piston is calculated as:

$$
p=p_{\text {out }}-f^{*} p_{\text {in }}
$$

Where: $p_{\text {out }}$ - the pressure in the pressure cavity; $p_{\text {in }}$ - the pressure in the suction cavity; $f$-ratio of area between pressure cavity and suction cavity.

And the resistance moment that pump feeds back to motor is calculated as:

$$
M=q^{*} p
$$

Model of Accumulator. Relationship between the cavity length and volume of accumulator is as below [5]:

$$
\begin{aligned}
& l_{e}=x_{0} * x_{1} \\
& V=l_{e}^{*} \pi^{*} d^{2} / 4
\end{aligned}
$$

Where: $l_{e}$-the cavity length of accumulator; $x_{0}$ - the initial length of accumulator cavity; $x_{1}$-displacement of piston; $d$-diameter of piston.

The flow quantity of braking liquid into the accumulator is calculated as below:

$$
q=v^{*} \frac{\pi}{4} * d^{2} * \frac{\rho(P)}{\rho(0)}
$$

Where: $v$ —piston moving speed; $\rho(P)$ —liquid density at pressure $P ; P$-Pressure in the accumulator.

And the dynamic equation of the piston is as below:

$$
F=l_{e}^{*} k-\frac{\pi}{4} * d^{2} * P
$$




$$
F=m^{*} \dot{v}=m^{*} \ddot{x}_{1}
$$

Where: $k$-spring stiffness; $m$-piston mass.

\section{Simulation}

Vehicle Parameters. Some domestic commercial vehicle was selected for the volume matching simulation. Its braking circuits are arranged as II type. Its parameters are shown as below:

Tab 1 Vehicle parameters

\begin{tabular}{|c|c|c|c|}
\hline Vehicle mass & Wheelbase & Distance centroid to front axle & Height of centroid \\
\hline $2750 \mathrm{~kg}$ & $3.44 \mathrm{~m}$ & $1.80 \mathrm{~m}$ & $0.64 \mathrm{~m}$ \\
\hline
\end{tabular}

Worst Case Selection. Pump and accumulator volume must be well matched for all kinds of braking situations. Among these situations, the negative mue jump while panic braking is the worst case certainly. In this case, deep slip will come to the wheel after mue jump. And ABS will take a strong decrement of pressure at corresponding wheel cylinder. The quantity of brake liquid flowing out of wheel cylinder is the most. So the simulation conditions are determined as followings.

Tab 2 Simulation conditions

\begin{tabular}{|c|c|c|}
\hline Vehicle initial speed & Master cylinder pressure & Road adhesion condition (Mue) \\
\hline $50 \mathrm{~km} / \mathrm{h}$ & $150 \mathrm{bar}$ & $1.0->0.3$ \\
\hline
\end{tabular}

Model Parameter Setting. Before simulation, parameters of accumulator, pump and motor should be initially identified. In model, resistance of the motor is $0.125 \mathrm{ohm}$, coil inductance is $9.34 \mathrm{e}-5 \mathrm{H}$, moment of inertia is $9.5 \mathrm{e}-5 \mathrm{~kg} * \mathrm{~m} 2$, and frictional torque is $0.3 \mathrm{~N}^{*} \mathrm{~m}$. the volume of accumulator is $5.3 \mathrm{ml}$, and its spring stiffness is $6200 \mathrm{~N} / \mathrm{m}$, and diameter of piston is $24 \mathrm{~mm}$. Eccentricity of pump is $1 \mathrm{~mm}$, and diameter of pump piston is $1 \mathrm{~mm}$.

ABS Control Logic. ABS controller monitors four wheels' slip, and four wheel cylinders' pressure is regulated independently.

\section{Results}

To judge whether the parameters of these parts can be applied to this vehicle or not, the volume of braking liquid that flows out the outlet valve on the same axle should be compared with the volume of liquid returned back to master cylinder by pump when ABS works at the worst case.

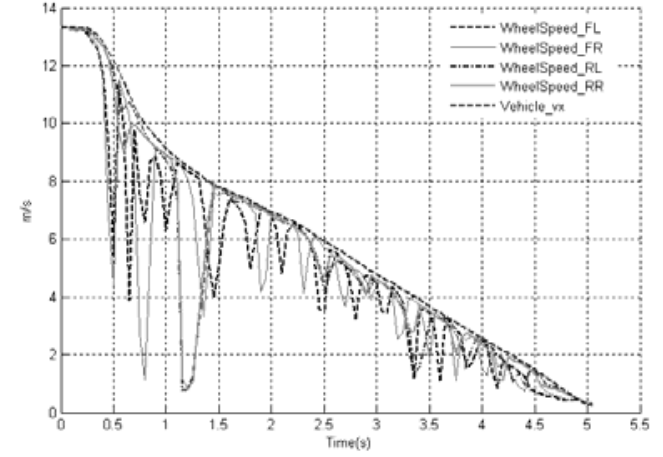

Fig 4 Wheel speed and vehicle speed

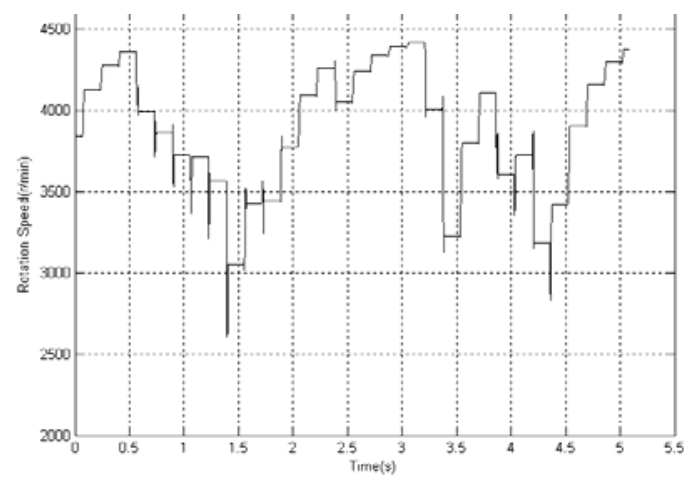

Fig 6 Motor rotation speed

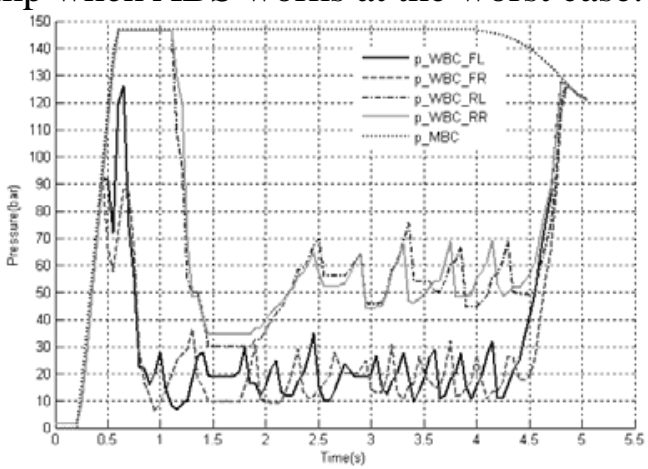

Fig 5 Wheel cylinder pressure

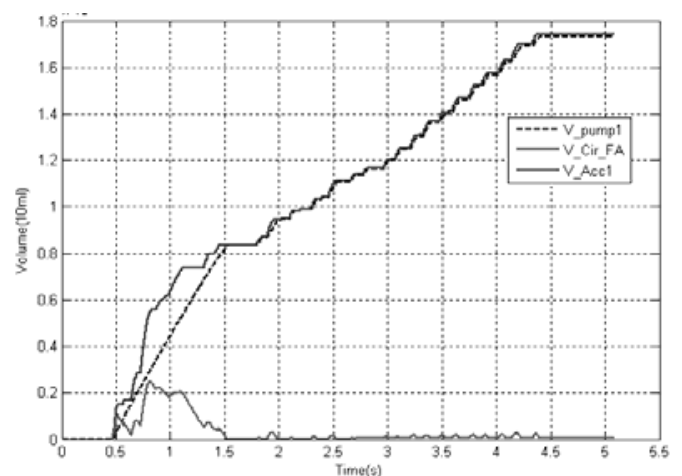

Fig 7 Liquid flow volume 
From these figures above, it can be seen that volume of accumulator is large enough for liquid flowing back at the worst case, and there is a certain redundancy. So the volume of accumulator and pump can be reduced properly. By this method work of volume matching for pump and accumulator can be carried out well, which can give a direction for hydraulic unit design.

\section{Reference}

[1] B. ZHANG, Z.D. LIU, Y.F. MA, et al. Journal of Agricultural Mechanization Research [J], 2007(1): 208-210 (in Chinese with English abstract)

[2] L.CHU, J.CHEN, L.YAO, et al. The 3rd International Conference on Engineering Design and Optimization (Ningbo, China, May. 25 28, 2012), published.

[3] Y.WANG, P.WANG, W.D.SU.Journal of Electric Power [J], 2010, 30(2):30-33.

[4] D.W. GAO. Research on Hydraulic Modulator Modeling and Brake Pressure Estimation for Vehicle Electronic Stability Program [D], Jilin University, Changchun, China. 2009:11-29

[5] R. TAO, H. ZHANG, et al. Transactions of the CSAE, 2010, 26(3): 135-139. 